\title{
EMPREENDEDORISMO NA ESCOLA: POSSIBILIDADE PARA PROJETAR E REALIZAR SONHOS
}

DOI: $10.48075 /$ ri.v24i1.26995

Andrielli Jorge da Silva ${ }^{1}$ Marcos Lübeck ${ }^{2}$

RESUMO: O empreendedorismo na escola é muito pertinente, pois pode articular situações reais e promover o protagonismo, bem como ativar um processo de ensino-aprendizagem por meio da interpretação e enfrentamento de acontecimentos que podem ocorrer dentro ou fora do ambiente escolar. Da mesma forma, pode possibilitar a idealização e a efetivação de determinadas aspirações, tanto individuais quanto coletivas. Portanto, apresentamos aqui um projeto de empreendedorismo realizado em 2018 e 2019 na Escola Municipal Najla Barakat, em Foz do Iguaçu/PR, o qual envolveu 22 (vinte e dois) estudantes do 50 ano do Ensino Fundamental, e que teve como propósito inicial contextualizar alguns conceitos matemáticos com vistas à realidade vivenciada pelos envolvidos. $\mathrm{Na}$ ocasião, apresentamos atividades e desenvolvemos práticas educativas destacando a importância do consumo sustentável e, nesse sentido, compartilhamos conhecimentos sobre diferentes tipos de empreendimentos, além de laborar para a concretização de um sonho coletivo daquela turma, que visava realizar um passeio de formatura a um parque aquático. Teoricamente, o projeto embasou-se em referenciais que versam sobre o empreendedorismo escolar, tais como Dolabela (2003; 2006; 2008) e Dornelas (2016) e, metodologicamente, seguiu princípios do trabalho colaborativo, conforme define Ferreira (2006). Assim, com esse projeto, concluímos que contextualizar o ensino de conceitos matemáticos com a realidade vivenciada pelos estudantes torna a aprendizagem mais efetiva, e que proceder de modo empreendedor, cooperativo e colaborativo produz muitos resultados positivos, tais como valores e o respeito mútuo, o desenvolvimento da autonomia, da criatividade e de várias habilidades matemáticas.

Palavras-chave: Empreendedorismo; Educação Financeira; Cooperativa Mirim.

\footnotetext{
${ }^{1}$ Mestranda em Ensino pela Universidade Estadual do Oeste do Paraná (UNIOESTE), campus de Foz do Iguaçu, Paraná, Brasil. Docente da Rede Municipal de Ensino de Foz do Iguaçu, Paraná, Brasil.

E-mail: andriellij@gmail.com. ORCID: https://orcid.org/0000-0003-4847-8671.

2 Doutor em Educação Matemática pela Universidade Estadual Paulista (UNESP), Rio Claro, São Paulo, Brasil. Docente do Curso de Matemática e do Programa de Pós-Graduação em Ensino (PPGEn), da Universidade Estadual do Oeste do Paraná (UNIOESTE), campus de Foz do Iguaçu, Paraná, Brasil.

E-mail: marcos.lubeck@unioeste.br. ORCID: https://orcid.org/0000-0001-6787-7083.
} 


\section{ENTREPRENEURSHIP IN SCHOOL: POSSIBILITY FOR DESIGNING AND REALIZING DREAMS}

ABSTRACT: Entrepreneurship at school is very relevant, as it can articulate real situations and promote protagonism, as well as activating a teaching-learning process through the interpretation and coping with events that may occur inside or outside the school environment. Likewise, it can enable the idealization and the realization of certain aspirations, both individual and collective. Therefore, we present here an entrepreneurship project carried out in 2018 and 2019 at the Municipal School Najla Barakat, in Foz do Iguaçu/PR, which involved 22 (twenty-two) students from the 5th year of elementary school, and whose initial purpose was to contextualize concepts mathematicians with a view to the reality experienced by those involved. On the occasion, we presented activities and developed educational practices highlighting the importance of sustainable consumption and, in this sense, we shared knowledge about different types of enterprises, in addition to working towards the realization of a collective dream of that group, which aimed to undertake a graduation trip to a water park. Theoretically, the project was based on references that deal with school entrepreneurship, such as Dolabela $(2003 ; 2006 ; 2008)$ and Dornelas (2014) and, methodologically, followed principles of collaborative work, as defined by Ferreira (2006). Thus, with this project, we concluded that contextualizing the teaching of mathematical concepts with the reality experienced by students makes learning effective, and that proceeding in an entrepreneurial, cooperative and collaborative way produces many positive results, such as values, mutual respect, the development of autonomy, creativity and various mathematical abilities.

Key Words: Entrepreneurship; Financial Education; Children's Cooperative.

\section{INTRODUÇÃO}

O Projeto Cooperativa Mirim Cooperlike foi desenvolvido com/para os estudantes do 5o ano da Escola Municipal Najla Barakat, em 2018 e 2019, no município Foz do Iguaçu/PR. No total, 22 (vinte e dois) estudantes, sob a supervisão e coordenação docente, participaram diretamente das atividades, onde as ações pretendiam desenvolver autonomia, criatividade, consciência crítica e a capacidade para lidar com determinadas situações problemas relacionadas, sobretudo, com a educação financeira, e assim, promover o processo de ensino-aprendizagem.

A ideia da Cooperativa iniciou no ano de 2018 , ocasião em que estudantes e docentes da escola completaram uma formação ofertada e desenvolvida pelo Instituto Sicoob. Então, ao concluir essa formação, foi criada a Cooperativa Mirim Cooperlike. Dessa forma, aplicouse à realidade um conjunto de conhecimentos técnicos e científicos que potencializou a capacidade dos envolvidos em agir, tomar decisões, traçar planos e organizar os recursos 
necessários para alcançar seus intentos, empreendendo para realizar sonhos, tudo isso ocorrendo dentro da esfera escolar.

Sem dúvida, a escola é um espaço primordial para trabalhar o empreendedorismo, uma vez que é considerada um lugar ideal para os estudantes obterem conhecimentos, experiências e aprendizagens que levarão para sua vida toda, seja como formação pessoal ou profissional. Dessa maneira, a escola é um importante ambiente de possibilidades para desenvolver ações e compartilhar conhecimentos, onde práticas criativas atreladas à teorias inovadoras têm amplo potencial e permitem variados alcances.

Para mais, a escola é um ambiente de ensino, e ensinar para empreender faz com que sempre surjam novas demandas. E uma delas é como ensinar para empreender. Destacamos que soluções para isso não são simples nem universais. Lembramos, ainda, que ser empreendedor não significa somente ter um negócio próspero ou um emprego bem sucedido. É algo mais, e que vai bem além, ou seja, uma pessoa empreendedora, em nosso juízo, é uma protagonista na sua vida, uma promotora de si, porém, ao mesmo tempo, é uma colaboradora para com os demais na sociedade em que todos vivem.

Com essa noção, o projeto visou proporcionar aos estudantes um novo sentido, agora voltado ao trabalho colaborativo para a realização de um sonho, uma aspiração coletiva que, no caso, era realizar uma excursão de formatura a um parque aquático, mas que, para ser concretizado, requeria uma série de exercícios cooperativos. Observe que, para estudantes na faixa etária de 10 (dez) anos, esta pode representar uma tarefa imensa. Contudo, a realização do projeto contou com a participação da escola, das famílias e da comunidade, em que todos, de forma direta ou indireta, auxiliaram e contribuíram para o sucesso do mesmo.

O projeto teve como foco fundamental apresentar, a partir de tarefas e ações práticas, conceitos matemáticos com vistas à realidade vivenciada pelos estudantes. E com base no planejamento do 5 o ano, onde apresentamos os conteúdos do sistema monetário e as quatro operações básicas, por meio de situações problemas, foi possível envolver os mesmos. Entretanto, diante de algumas dificuldades observadas quanto ao aprendizado dos conteúdos, sentimos a necessidade de implementar aulas diferenciadas com a finalidade de dar um significado maior e contextualizar os conceitos matemáticos em realce, para assim facilitar a aprendizagem.

Na ocasião, desenvolvemos algumas práticas educativas destacando a importância do consumo das pessoas ser sustentável, e nesse sentido, compartilhamos conhecimentos 
sobre diferentes empreendimentos, enfatizando o quanto é importante e necessário ter cuidado e atenção para com o consumismo, proporcionando aos estudantes subsídios para que desenvolvessem um pensamento crítico. Isso é importante, pois vivemos num mundo capitalista e o consumismo está presente no cotidiano das pessoas, sendo necessária a implantação de projetos voltados ao empreendedorismo consciente, à educação financeira e à sustentabilidade, já nas escolas, nos anos iniciais do ensino básico.

É fundamental que os estudantes, desde cedo, saibam lidar e valorizar seu dinheiro, mas, ao mesmo tempo, tenham consciência de que não devem viver unicamente em função deste. Além disso, precisam de atitudes sensatas para usar de maneira adequada seus recursos econômicos, planejando gastos e consumindo com responsabilidade. E se forem vender algo, prezar pela qualidade do produto, estabelecer metas e formas atrativas para negociar, fazer os cálculos referentes aos custos e lucros, e valorizar o trabalho em equipe. Nestes pontos, o projeto satisfez o processo de ensino-aprendizagem e ainda estimulou o empreendedorismo, promovendo atividades como a confecção e a venda de produtos, tais como lápis com ponteiras, chaveiros, gelatinas, brigadeiros etc., o que proporcionou perpassar temas da educação financeira.

\section{EMPREENDEDORISMO NA EDUCAÇÃO BÁSICA}

Quando ouvimos falar de empreendedorismo, logo pensamos em algo relacionado ao meio empresarial, mas Dolabela (2008, p. 10) frisa bem que "o aprendizado do conteúdo empreendedor é fundamental em todos os cursos de todas as áreas do conhecimento, nos lembrando que o empreendedorismo é um fenômeno cultural", e que, muito embora o termo empreendedorismo tenha a sua origem em um contexto empresarial, em qualquer outra área podemos praticar o empreendedorismo, pois o empreendedor é um ser atuante no meio em que vive. Nesse sentido, Dolabela (2003, p. 35) define empreendedorismo como "uma forma de ser", defendendo a ideia de que podemos empreender em diversas situações, não apenas no mundo dos negócios. Logo, podemos trabalhar empreendedorismo na escola, sem empecilhos ou ressalvas restritivas para iniciar ações sociais, ainda que nos anos iniciais da educação básica.

Conforme Dornelas (2016, p. 31), "o movimento do empreendedorismo no Brasil começou a tomar forma na década de 1990, quando entidades como o Serviço Brasileiro de Apoio às Micro e Pequenas Empresas (SEBRAE) e a Sociedade Brasileira para Exportação de 
Software (SOFTEX) foram criadas, a fim de dar suporte aos empreendimentos que estavam surgindo nesses segmentos, pois os empreendedores não tinham conhecimento suficiente na área de administração de negócios". Na época, o termo empreendedorismo estava totalmente voltado a esse meio, e por isso o termo, por vezes, ainda leva a pensar primeiro nessa área em particular.

Mas esse olhar voltado ao meio empresarial começou a mudar com a criação da Lei de Diretrizes e Bases da Educação Nacional (LDBEN), no 9.394 de 1996, a qual apresenta uma proposta que tem por finalidade desenvolver a formação comum no indivíduo, bem como fornecer meios para que os estudantes prosperem, como assegura o seu artigo 22 , onde se lê que "a educação básica tem por finalidade desenvolver o educando, assegurar-Ihe a formação comum indispensável para o exercício da cidadania e fornecer-Ihe meios para progredir no trabalho e em estudos posteriores" (BRASIL, 1996, p. 8). Embora a palavra não esteja literalmente na LDBEN, é evidente pela sua letra, que o empreendedorismo, quando desenvolvido na escola, pode proporcionar subsídios "para progredir" no trabalho e estudos.

Já a Organização das Nações Unidas para Educação, Ciência e Cultura (UNESCO), apresenta um quinto pilar da educação: "aprender a empreender", como uma estratégia para enfrentar os problemas sociais e econômicos da atualidade e cumprir as metas do Programa Educação Para Todos, e que deve ser adicionado aos demais pilares - "Aprender a conhecer", "Aprender a fazer", "Aprender a conviver" e "Aprender a ser" - propostos em 1996 no relatório intitulado Educação para o Século XXI, o qual foi elaborado para a UNESCO (DELORS et al., 1998). O documento contendo os cinco pilares foi aprovado em 2002, em Havana - Cuba, e publicado na revista do PRELAC, Ano 1, n. 0, em agosto de 2004.

Dornelas (2016, p. 28) destaca ainda que "o interesse pelo empreendedorismo vem se destacando e chamando a atenção de muitas organizações e entidades multinacionais, como, por exemplo, o Fórum Econômico Mundial, realizado em Davos - Suíça, no ano de 2009, no qual o tema empreendedorismo teria sido discutido de forma recorrente. Nessa reunião, denominada de Educando a próxima onda de empreendedores, após debates e análises, foram feitas algumas recomendações com o intuito de reforçar o ensino de empreendedorismo para que os jovens consigam suprir demandas e desafios do século XXI.

Dentre as recomendações, o autor destaca:

- Desenvolver habilidades de liderança e conhecimento do mundo e do ambiente no qual vivem, para que consigam superar os desafios das próximas décadas.

- Enfatizar a educação empreendedora como parte-chave da educação formal 
em todos os níveis.

- Desenvolver o empreendedorismo como tema transversal, não apenas como disciplina.

- Utilizar a interatividade como mote da pedagogia educacional, com foco na experimentação, na ação e na análise e solução de problemas.

- Ampliar o uso da tecnologia no ensino tanto para ganhar escala e aumentar a abrangência do tema como para possibilitar a criação de material didático inovador e interativo (DORNELAS, 2016, p. 28).

Cabe destacar, também, que

[...] a educação financeira apresenta uma contribuição imensa para sociedade, pois a participação nela de forma crítica de cada indivíduo-consumidor proporciona uma mudança significativa no ambiente ao seu redor. Na sociedade ainda existem muitas pessoas que pensam que a educação financeira serve apenas para aprender a poupar, para futuramente ter recursos financeiros disponíveis em casos de emergência (XISTO, 2020, p. 55).

Atualmente, a Base Nacional Comum Curricular (BNCC) é o documento oficial que rege a educação no Brasil em âmbito nacional, e desse modo, é importante destacar como ela aborda esse assunto. A BNCC está organizada em unidades temáticas, e compondo a unidade temática de Números, temos o estudo de conceitos básicos de economia e finanças, onde o objetivo é propor aos alunos uma educação financeira. Portanto, temos que um

[...] aspecto a ser considerado nessa unidade temática é o estudo de conceitos básicos de economia e finanças, visando à educação financeira dos alunos. Assim, podem ser discutidos assuntos como taxas de juros, inflação, aplicações financeiras (rentabilidade e liquidez de um investimento) e impostos. Essa unidade temática favorece um estudo interdisciplinar envolvendo as dimensões culturais, sociais, políticas e psicológicas, além da econômica, sobre as questões do consumo, trabalho e dinheiro. É possível, por exemplo, desenvolver um projeto com a história, visando ao estudo do dinheiro e sua função na sociedade, da relação entre dinheiro e tempo, dos impostos em sociedades diversas, do consumo em diferentes momentos históricos, incluindo estratégias atuais de marketing. Essas questões, além de promover o desenvolvimento de competências pessoais e sociais dos alunos, podem se constituir em excelentes contextos para as aplicações dos conceitos da matemática financeira e também proporcionar contextos para ampliar e aprofundar esses conceitos (BRASIL, 2017, p. 269).

Como neste trecho na BNCC, diversos outros mencionam habilidades e objetos do conhecimento que permeiam contextos de matemática financeira e de empreendedorismo, fato que vai ficando cada vez mais acentuado conforme passamos dos anos iniciais aos finais da educação básica. E que é algo que não se restringe apenas a disciplina de matemática. Aliás, a BNCC diz que a escola precisa "proporcionar uma cultura favorável ao desenvolvimento de atitudes, capacidades e valores que promovam o empreendedorismo [...], entendido como competência essencial ao desenvolvimento pessoal, à cidadania ativa, 
à inclusão social e à empregabilidade" (BRASIL, 2017, p. 466), fato que transpassa todas as disciplinas curriculares.

No que tange os itinerários formativos que as escolas podem oferecer, a BNCC cita o empreendedorismo, que "[...] supõe a mobilização de conhecimentos de diferentes áreas para a formação de organizações com variadas missões voltadas ao desenvolvimento de produtos ou prestação de serviços [...]" (BRASIL, 2017, p. 478). Num último excerto, de fato, "há hoje mais espaço para o empreendedorismo [...] e cresce a importância da educação financeira e da compreensão do sistema monetário contemporâneo nacional e mundial, imprescindíveis para uma inserção crítica e consciente no mundo" (BRASIL, 2017, p. 568).

O Referencial Curricular do Paraná (RCP), levando em conta a aprovação da BNCC, atualizou seu currículo estadual incorporando os temas em questão. Além disso, considerou outros documentos que abordam a educação para o consumo e a educação financeira e fiscal, enfim, uma série de temas contemporâneos, assumindo que cabe aos sistemas de ensino tratá-las de forma contextualizada.

Nesse sentido, diz que

[...] cabe aos sistemas e redes de ensino, assim como às escolas, em suas respectivas esferas de autonomia e competência, incorporar aos currículos e às propostas pedagógicas a abordagem de temas contemporâneos que afetam a vida humana em escala local, regional e global, preferencialmente de forma transversal e integradora. Entre esses temas, destacam-se: direitos da criança e do adolescente (Lei no 8.069/1990), educação para o trânsito (Lei no 9.503/1997), educação ambiental (Lei no 9.795/1999, Parecer CNE/CP no 14/2012 e Resolução CNE/CP no 2/2012), educação alimentar e nutricional (Lei no 11.947/2009), processo de envelhecimento, respeito e valorização do idoso (Lei no 10.741/2003), educação em direitos humanos (Decreto no 7.037/2009, Parecer CNE/CP no 8/2012 e Resolução CNE/CP no 1/2012), educação das relações étnico-raciais e ensino de história e cultura afro-brasileira, africana e indígena (Leis no 10.639/2003 e 11.645/2008, Parecer CNE/CP no 3/2004 e Resolução CNE/CP no 1/2004), bem como saúde, vida familiar e social, educação para o consumo, educação financeira e fiscal, trabalho, ciência e tecnologia e diversidade cultural (Parecer CNE/CEB no 11/2010 e Resolução CNE/CEB no 7/2010) (PARANÁ, 2018, p. 7).

Levando em conta que o intuito da criação do projeto da Cooperativa Mirim surgiu da necessidade de ensinar os conteúdos propostos pelo Planejamento Municipal de Foz do Iguaçu de forma contextualizada, em atendimento ao que preconizam os documentos oficiais, devemos destacar um documento importante que orienta a Educação Municipal, que é o Currículo da Associação dos Municípios do Oeste do Paraná (AMOP), onde se lê que:

Ainda na unidade temática números, destaca-se a matemática financeira, que deverá oferecer orientações e informações que favoreçam a atuação consciente do cidadão. Ela não é apenas o trabalho mecânico com cálculo de porcentagens, mas 
instiga uma mudança de atitudes com relação às compras, às vendas, ao planejamento de sua mesada, aos empréstimos bancários realizados por seus pais, bem como aos rendimentos das aplicações financeiras, à análise dos impostos/tributos pagos pelos cidadãos e ao retorno desses como políticas públicas garantidas aos cidadãos pelos tributos pagos, entre outros aspectos (AMOP, 2020, p. 482).

Devido a esses documentos, falar em ensino para o empreendedorismo na escola tem se tornado um assunto recorrente, que ganha cada vez mais espaço e é discutido abertamente por pesquisadores, professores e envolvidos com educação. Nesse sentido, para Souza (2012, p. 15), “o ensino do empreendedorismo, ou de qualquer outra "habilidade" ou "competência", na escola, transfere para os estudantes uma determinada concepção de mundo, de pessoa, de sociedade, e que tem o poder de formar, conformar ou deformar a consciência do aprendiz."

No ponto de vista de Dornelas (2016), o empreendedorismo é compreendido como atitude, sendo mais importante do que o conhecimento técnico. Para esse autor, os empreendedores são visionários, antevendo o futuro, da sua vida e sua comunidade, e têm a capacidade de implementar seus sonhos e tomar decisões na hora adequada, mesmo ante à diversidade, transformando ideias abstratas em algo concreto e ultrapassando obstáculos com uma vontade ímpar de "fazer acontecer". São inconformados diante da rotina e adoram o trabalho que realizam, criando valores para a sociedade.

Já no ponto de vista de Xisto (2020, p. 54), "a educação financeira é um conteúdo essencial nas escolas, principalmente no ensino fundamental. Estudantes devem ter conhecimento desde cedo sobre a importância de se planejar, controlar, saber investir e ser consciente em suas escolhas para o futuro." Como se vê, é inegável a importância do empreendedorismo escolar, e por isso existe todo um trabalho para que seja empregado como uma componente curricular, destacado nas leis e também pelos autores, seja como disciplina ou por meio de projetos, como descrevemos a seguir, trazendo uma maneira atrativa de se abordar essa temática de forma a contribuir com o processo de ensinoaprendizagem dos estudantes, visando seu desenvolvimento integral.

\section{UM PROJETO DE EMPREENDEDORISMO NA ESCOLA}

Como docentes da Rede Municipal de Ensino há mais de cinco anos, lecionando em turmas do 10 ao 5ㅇan ano, nas mais diferentes áreas, frequentemente, ouvimos dos estudantes 
palavras de aversão às disciplinas ou aos conteúdos. Por vezes, ainda, o estudante, para se apropriar dos temas trabalhados em sala de aula, quer saber por que precisa aprender aquilo, razão pela qual os professores estão sempre em busca de subsídios para contextualizar os conteúdos programáticos com a realidade na qual os estudantes estão inseridos. E considerando as adversidades, a necessidade de trabalhar o empreendedorismo e a conscientização financeira, desenvolvemos o Projeto Cooperativa Mirim Cooperlike.

A Cooperativa Mirim Cooperlike foi criada no início do ano de 2018 e encerrou suas atividades em dezembro de 2019 , tendo em vista que a turma com a qual o projeto foi desenvolvido concluiu o 5으. ano, encerrando o ciclo dos anos iniciais do ensino fundamental. Além disso, a supervisora do projeto se licenciou para cursar o mestrado. A Cooperativa, aliás, tinha como objetivo principal melhorar o desempenho dos estudantes no processo de ensino-aprendizagem, especialmente nos conteúdos de números e suas operações.

O projeto ganhou espaço almejando com que os estudantes compreendessem as diversas situações problemas presentes no seu dia a dia e para que pudessem entender e aprender diferentes formas de cálculos para solucionar tais situações, o que é uma dificuldade. Então, estruturamos a Cooperativa na escola, onde o intuito primeiro desejado era o de que eles compreendessem melhor as situações problemas da matemática, aliadas a realidade cotidiana vivenciada por eles, e assim as resolvessem. Porém, felizmente, o projeto foi mais longe. Vale destacar que a Cooperativa contou com o apoio do Instituto Sicoob.

O Instituto Sicoob foi criado em 2004, na cidade de Maringá/PR, onde tinha por objetivo difundir a cultura cooperativista e contribuir para a promoção do desenvolvimento sustentável das comunidades. A partir daí a instituição se expandiu nacionalmente e passou a desenvolver, dentre outros, programas e projetos divididos em três eixos: Cooperativismo e Empreendedorismo, Cidadania Financeira e Desenvolvimento Sustentável (SICOOB, s.d.).

Dentro do Eixo Cooperativismo e Empreendedorismo são desenvolvidos Programas e Projetos, e o Programa Cooperativa Mirim faz parte desse eixo, fomentando a formação de cooperativas nas escolas e instituições que atendam crianças e adolescentes. Sendo assim, a Cooperativa Mirim é uma associação de estudantes que, sob a supervisão e direção de um professor orientador, unem-se voluntariamente visando satisfazer anseios e necessidades comuns, por meio da vivência e prática do cooperativismo (SICOOB, s. d.).

Essa vivência do cooperativismo, e do empreendedorismo, traz grandes descobertas para a sala de aula. Nisto, de início, notamos que os estudantes estavam inseridos num mundo de consumismo e de ganhar tudo, que não valorizavam as coisas que ganhavam, e 
que não tinham a noção dos preços dos produtos e que ignoravam o valor do dinheiro. Talvez não valorizavam mais o dinheiro porque não sabiam como era difícil conquistá-lo. Então o projeto ganhou mais um objetivo, a saber, o desenvolvimento de uma consciência financeira nos estudantes, por meio de atividades como rodas de conversas sobre a importância de poupar, de pensar antes de adquirir um produto novo, de pesquisar preços. Os alunos também tiveram uma palestra de formação com uma equipe do Instituto Sicoob que é capacitada em educação financeira, momento que receberam orientações financeiras.

Após as formações, chegou a hora de colocar em prática tudo aquilo que aprenderam na teoria. Portanto, antes de começar suas atividades como uma Cooperativa, formou-se uma diretoria escolhida através de uma Assembleia Geral, realizada com alunos e pais, na qual aprovou-se também o Estatuto, onde alguns direitos e deveres são assegurados e que devem ser cumpridos, e definiu-se a cota capital no valor de $\mathrm{R} \$ 10,00$ (dez reais), que era o investimento que cada um deveria fazer para se associar a Cooperativa, como podemos ver na Figura 1. Daí em diante iniciaram os demais trabalhos.

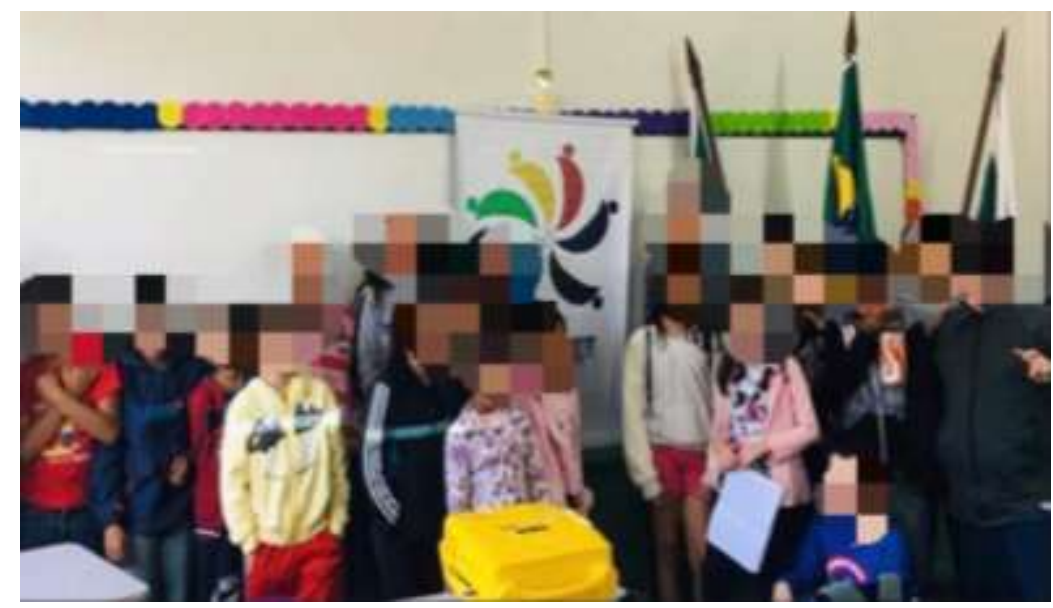

Figura 1: Assembleia Geral para a escolha da diretoria. Fonte: Arquivo pessoal.

Depois de estudar conceitos como poupança, investimento e rendimento, pensamos em alternativas para fazer o dinheiro render, pois, afinal de contas, um bom valor deveria ser arrecadado, já que objetivo unânime era um passeio custeado pelos lucros gerados pelo engajamento na Cooperativa. Aqui cabe um aparte para destacar que, metodologicamente, as ações seguiram princípios do trabalho colaborativo.

Elucidando melhor a metodologia adotada, podemos dizer que: 
Na colaboração, cada indivíduo participa da maioria das decisões: escolher a meta, definir as estratégias, definir as tarefas, avaliar os resultados; e o faz consciente de que é algo realmente importante para ele, algo que tanto beneficia o grupo como um todo, quanto a ele diretamente. [...]. Para Hall e Wallace (1993, p. 105), os relacionamentos de colaboração implicam que "todos os parceiros valorizem esta como forma de trabalhar o suficiente para comprometerem-se a fazê-lo: eles escolhem se engajar em um trabalho conjunto para alcançar metas comuns" [...]. Um ponto relevante na constituição de grupos colaborativos é, a nosso ver, a percepção da participação no grupo como fonte de aprendizagem (FERREIRA, 2006, p. 152).

Durante as discussões no grupo surgiram várias ideias, mas era necessário que fosse algo simples e prático, além de ser criado pelos próprios alunos. Dentre as propostas, optouse por confeccionar artesanatos, como ponteiras de lápis e chaveiros, além de outros produtos que seriam revendidos, como gelinhos e balas, e a venda de produtos artesanais que os estudantes produziram, como gelatinas e brigadeiros. Os produtos seriam vendidos na escola e a proposta visava estimular o empreendedorismo, como vemos na Figura 2.

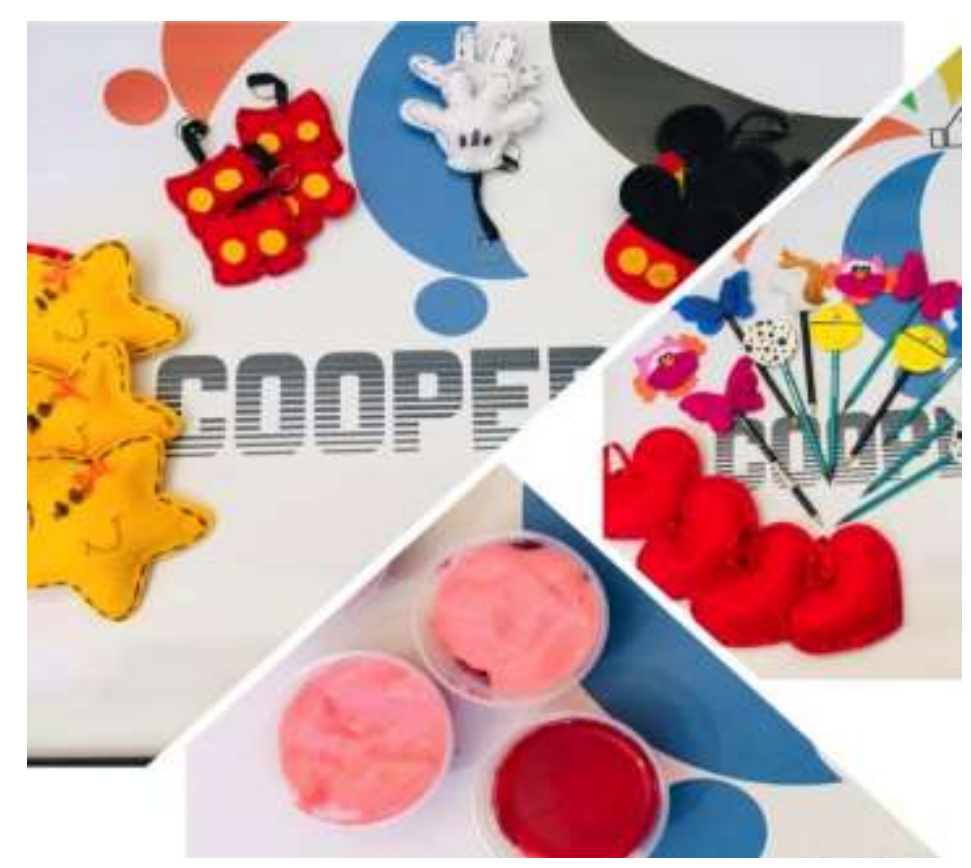

Figura 2: Produtos confeccionados para a venda. Fonte: Arquivo pessoal.

Os alunos também precisaram aprender a calcular e a ter noções sobre custos, lucros e prejuízos. Isso foi importante porque, a cada ciclo de vendas, faziam os cálculos dos gastos com base nas notas fiscais de compra para saber o valor do lucro arrecadado. Aprender esses cálculos foi gratificante, pois notamos grande envolvimento e empolgação. Toda vez que o caixa era fechado era uma euforia para saber quanto houve de lucro e como estaria o caixa com seu valor atualizado. Essa ação era realizada pelos diretores financeiros da diretoria, com auxílio da docente, e tudo ficava registrado no Livro Caixa da Cooperativa, juntamente com as notas fiscais disponíveis para consulta de todos os demais associados. 
Para confeç̧ão e preparo dos produtos foram formados subgrupos, como vemos nas Figuras 3 e 4, que se alternavam ao longo das semanas em encontros, e nesses encontros de preparação e produção, descobríamos habilidades dos estudantes até então desconhecidas. Eles tinham cada um a sua função, de acordo com suas habilidades, como, por exemplo, vender, receber o dinheiro, passar o troco, divulgar etc., e mesmo os mais retraídos, que se recusaram nas primeiras tentativas a participar, se envolveram nas atividades com o tempo. Ressaltamos que todos os produtos eram vendidos no horário do intervalo, no momento do recreio escolar. Importante destacar aqui o apoio da escola para que o sonho dos estudantes se realizasse.

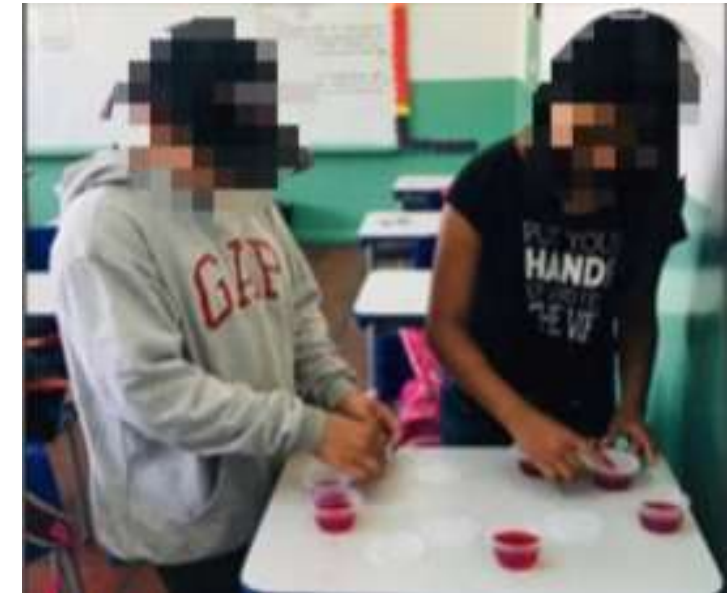

Figura 3: Alunos trabalhando em grupo. Fonte: Arquivo pessoal.

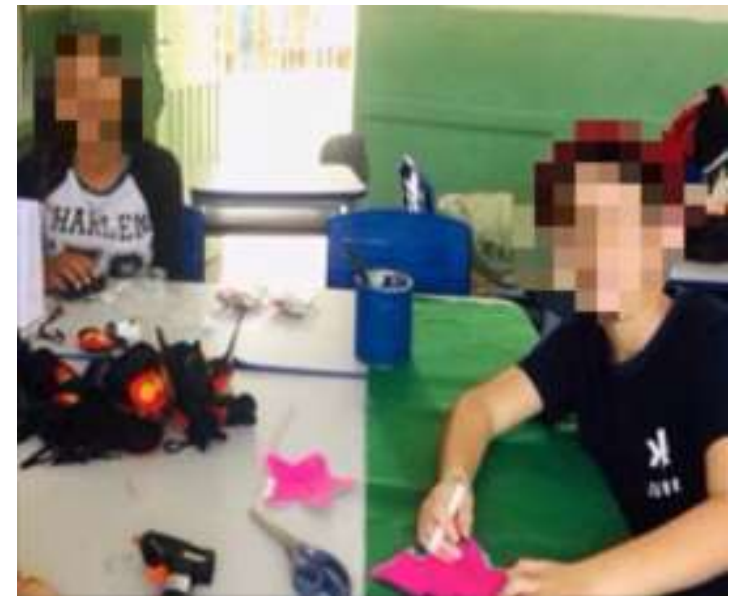

Figura 4: Alunos confeccionando produtos. Fonte: Arquivo pessoal.

Outro fato notável é que os alunos receberam pedidos da escola para a confecção de prendedores de roupas decorados para a comemoração do dia das mães e um pedido para o dia dos pais. Outra encomenda que gerou orgulho e muita felicidade foi a do próprio Instituto Sicoob, para o qual os alunos tiveram que produzir 200 (duzentos) chaveiros. Não bastasse, receberam mais uma encomenda de 200 (duzentos) chaveiros de coração para o casamento de um casal de pais de um dos associados, e tudo isso gerou euforia e foco, pois se sentiam mais empreendedores e acreditavam cada vez mais em seu potencial e trabalho.

Sem dúvida, o desenvolvimento real do projeto tornou mais efetiva a aprendizagem. Nisto, a valorização do dinheiro mudou a perspectiva sobre as atividades que, num primeiro momento poderiam ser vistas como uma brincadeira, passaram a vistas como coisa séria, e a aprendizagem começou a ocorrer de forma gradual, leve, sempre aliando o projeto a outras disciplinas, como português, artes ou ciências, com produções textuais, leituras e reflexões sobre o consumo excessivo, consciência ambiental, boas atitudes, onde trabalhamos com as 
temáticas da economia doméstica e economia sustentável, por meio das quais abordamos questões sobre reaproveitamento, reciclagem, sustentabilidade, dentre outras.

Como destaca Teixeira (2012, p. 101), “o empreendedorismo não existe por si só, ele está articulado com outros saberes. [E] tornar-se empreendedor significa adquirir, aplicar e construir um conjunto de competências e conhecimentos." Com o projeto, notamos uma clara construção de conhecimentos pelos estudantes. Além disso, para toda atividade desenvolvida, havia uma avaliação sobre a participação e o comprometimento dos envolvidos nela, tornando visível o crescimento de cada um dia após dia.

\section{RESULTADOS PARA ALÉM DA SALA DE AULA}

Atitudes dos estudantes, como pensar antes de consumir ou comprar algo para avaliar se realmente é necessário, ou ter a preocupação com os gastos de energia e de água em casa, mostram que estes passaram a compreender melhor a importância do dinheiro em suas vidas, mas, para além disso, passaram a perceber o impacto de suas ações no futuro. Igualmente, o projeto possibilitou a vivência com uma temática pouco comum na sua rotina de sala de aula, embora muito importante na vida pessoal de cada um.

Em um relato de uma mãe, esta disse que o trabalho que estava sendo desenvolvido na escola era maravilhoso, pois auxiliava na educação que ela dava dentro de casa, que apesar das dificuldades para educar um filho, quando a escola e a família estão no mesmo caminho, tudo se torna mais fácil, dizendo ainda que se admirou de ver seu filho falando da importância de economizar dinheiro por meio de um consumo consciente. Outra mãe ficou emocionada ao relatar que a filha sugeriu ao pai, desempregado na ocasião, a produzir bolos e doces e sair para vender de forma autônoma, tornando-se assim um empreendedor.

Notadamente, o desenvolvimento do projeto gerou muitos resultados positivos para além dos esperados na sala de aula. Contudo, devemos ressaltar que na escola igualmente ficou perceptível o comprometimento dos estudantes com as diversas atividades e matérias, com o respeito, a solidariedade e a cooperação com o próximo e a vontade de estar sempre ajudando e colaborando. Isso mostra que o trabalho desenvolvido atingiu sua finalidade, apresentando resultados satisfatórios em termos educacionais.

Com relação aos objetivos propostos no Planejamento Anual do Município de Foz do Iguaçu para o 5o ano do ensino fundamental, que refere-se ao desenvolvimento de habilidades relacionadas ao sistema monetário e as quatro operações por meio de situações problemas, percebemos o interesse e o desenvolvimento dos estudantes em relação as 
operações básicas associadas as interpretações e resoluções de situações problemas. Nisto, corroborando com Daga e Bezerra (2017, p. 126), vimos que, "quando dialogamos com a realidade do aluno não estamos abrindo mão da formalidade da matemática, apenas estamos contextualizando o ensino, o que ajuda o aluno a construir o conhecimento."

Como Dolabela (2006, p. 29) propõe, “o empreendedor é alguém que sonha e busca transformar seu sonho em realidade", e o sonho da turma culminou com a realização do passeio, realizado no dia 03 de dezembro de 2019, quando todos foram ao parque aquático, como vemos na Figura 5. Foi um dia muito divertido, e estando localizado o parque próximo a um shopping da cidade, ao sair do mesmo, o destino foi o shopping, onde os estudantes fizeram um lanche numa famosa rede de comida rápida, porque a maioria ainda não tinha provado esse tipo de lanche. E para finalizar o dia de passeio, assistiram um filme animado e divertido, como vemos na Figura 6. Aliás, poucos estudantes conheciam uma sala de cinema. Todos os passeios, lanches, sorvetes, ingressos e o transporte que levou os estudantes foram bancados com o dinheiro arrecadado por meio da Cooperativa Mirim Cooperlike.

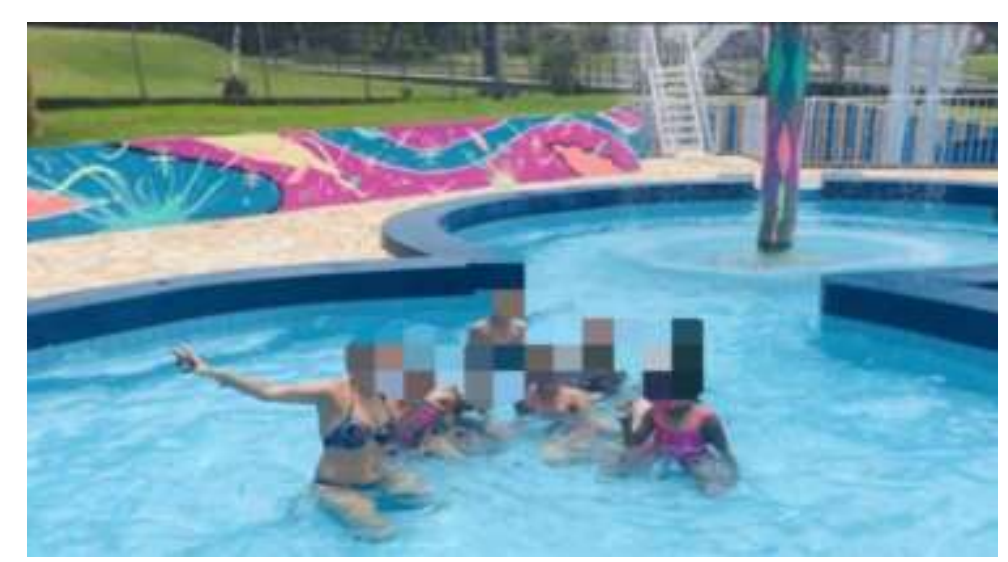

Figura 5: Passeio ao Parque Aquático. Fonte: Arquivo pessoal.

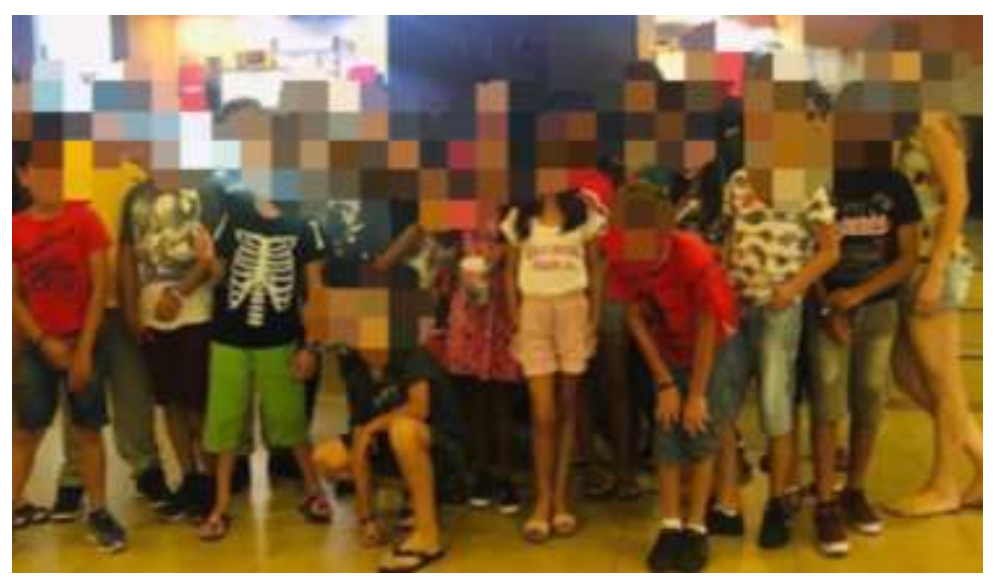

Figura 6: Visita ao Cinema no Shopping. Fonte: Arquivo pessoal. 
Ao final do projeto, concluímos que é importante e necessário educar os estudantes em relação a um uso consciente do dinheiro, e isso é preciso fazer desde muito cedo, pois, infelizmente, entre outros fatores, pode-se dizer que muitos pais não têm conhecimentos sobre educação financeira para ensinar seus filhos, identificando com eles aquilo que é primordial ser comprado, evitando assim que se tornem adultos endividados e frustrados.

Além disso, os estudantes aprenderam que podem ajudar suas famílias a organizar suas finanças, não apenas com dinheiro em espécie, mas evitando desperdícios, como, por exemplo, consumir água com responsabilidade, evitar de deixar as luzes acesas pela casa, não desperdiçar alimentos, pesquisar preços de produtos antes de comprar, como outras ações que podem fazer a diferença no orçamento familiar no final do mês.

Trabalhar o tema com os estudantes, que ainda são crianças, foi um grande desafio, haja vista que, para falar de empreendedorismo na escola, é preciso olhar atentamente para o seu desenvolvimento. E mais, para obter êxito, sair da zona de conforto é essencial. É preciso deixar a sala de aula, a frente do computador, e ir além. Para isso, são necessários inúmeros momentos de pesquisa, reflexão e adaptação dos conteúdos à realidade.

Por fim, fica a palavra de que discutir e praticar o empreendedorismo com alunos dos anos iniciais do ensino fundamental era algo que poucos acreditavam ser possível, mas que, com os resultados satisfatórios obtidos, mostramos que é possível, desde que todos os envolvidos se interessem, se empenhem, trabalhem de modo colaborativo, ponham em prática a criatividade e despertem para o mundo que está além das paredes das salas de aula. Essa é a compreensão de ser empreendedor, de alguém que empreende esforços em todos os passos da vida, por vezes sozinho, outras tantas em colaboração com mais pessoas. 


\section{REFERÊNCIAS}

AMOP. Associação dos Municípios do Oeste do Paraná. Currículo Básico para a Escola Pública Municipal - Educação Infantil - Rede Pública Municipal - Região da AMOP. Cascavel: AMOP, 2020.

BRASIL. Ministério da Educação e Cultura. Lei de Diretrizes e Bases da Educação Nacional: no 9394/96, de 20 de dezembro de 1996. Estabelece as Diretrizes e Bases da Educação Nacional. Brasília: MEC, 1996.

BRASIL. Ministério da Educação e Cultura. Base Nacional Comum Curricular. Brasília: MEC, 2017.

DAGA, I. C.; BEZERRA, R. C. Ensino de Matemática: contextualização da matemática financeira. Ideação. v. 19, n. 1, 1. sem. 2017, p. 113-128.

DELORS, J. et al. Educação: um tesouro a descobrir. Relatório para a UNESCO da Comissão Internacional sobre a Educação para o século XXI. São Paulo: Cortez, 1998.

DOLABELA, F. Pedagogia empreendedora. São Paulo: Cultura, 2003.

DOLABELA, F. O Segredo de Luísa. São Paulo: Cultura, 2006.

DOLABELA, F. Oficina do Empreendedor: a metodologia que ajuda a transformar conhecimento em riqueza. Rio de Janeiro: Sextante, 2008.

DORNELAS, J. C. de A. Empreendedorismo transformando ideias em negócios. São Paulo: Empreende/Atlas, 2016.

FERREIRA, A. C. O Trabalho Colaborativo como Ferramenta e Contexto para o Desenvolvimento Profissional: compartilhado experiências. In: NACARATO, A. M.; PAIVA, M. A. V. (org.). A Formação do Professor que Ensina Matemática: perspectivas e pesquisas. Belo Horizonte: Autêntica, 2006, p. 149-166.

PARANÁ. Secretaria de Estado da Educação. Referencial Curricular do Paraná: princípios, direitos e orientações. Curitiba: SEED, 2018.

SICOOB. Programas e Projetos. [s. d.]. Disponível em: https://www.institutosicoob.org.br. Acesso em: 26 fev. 2021.

SOUZA, S. A. de. A introdução do empreendedorismo na educação brasileira: primeiras considerações. Educação e Linguagem. v. 15, n. 26, 20 sem. 2012, p. 77-94.

TEIXEIRA, C. M. M. Educação para o Empreendedorismo: um estudo sobre o Projeto Nacional de Educação para o Empreendedorismo. Dissertação (Mestrado em Intervenção Social, Inovação e Empreendedorismo), Universidade de Coimbra, Coimbra, 2012. 
UNESCO. Uma trajetória para a educação para todos. Revista PRELAC, Ano 1. n. 0, 2. sem. 2004. Disponível em: http://unesdoc.unesco.org/images/0013/001372/137293por.pdf. Acesso em: 26 fev. 2021.

XISTO, L. P. Educação Financeira na Educação de Jovens e Adultos (EJA): buscando uma visão empreendedora para estudantes adultos no município de Irupi - ES. Dissertação (Mestrado em Educação Matemática), Universidade Federal de Juiz de Fora, Juiz de Fora, 2020.

Recebido em 03 de março de 2021.

Aprovado em 03 de maio de 2021.

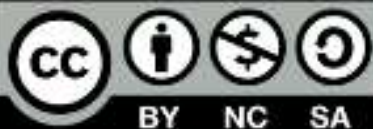

